\title{
Gastropod assemblages as indicators of sediment metal contamination in mangroves of Dumai, Sumatra, Indonesia.
}

\begin{abstract}
Impacts of heavy metal concentrations in sediments on the gastropod community structure were assessed in the coastal waters of Dumai, Sumatra, Indonesia. The objective of this study was to relate the levels of heavy metal pollution with the changes of gastropod community structure in the study area. Concentrations of $\mathrm{Cd}, \mathrm{Cu}, \mathrm{Pb}, \mathrm{Zn}, \mathrm{Ni}$, and $\mathrm{Fe}$ in surface sediments collected from five sampling stations were analyzed and correlated with the abundance, species richness, and diversity of gastropod populations. Sediments at stations with more anthropogenic activities accumulated higher concentrations of heavy metals and consequently displayed lower abundances, lower species richness and diversity; while stations with lower heavy metal concentrations in sediments showed the opposite pattern in gastropod community metrics. The above findings are complemented by significant negative correlations $\mathrm{p}<0.05-0.01$ ) between concentrations of $\mathrm{Cd}, \mathrm{Cu}, \mathrm{Pb}, \mathrm{Zn}$, and $\mathrm{Ni}$ in the sediments and gastropod abundance and species richness. Among the metals analyzed, $\mathrm{Cu}$ and $\mathrm{Zn}$ had strongest negative correlations with the gastropod diversity which suggests that these metals may be the most detrimental to gastropod populations in the mangrove area of Dumai coastal waters.
\end{abstract}

Keyword: Heavy metals; Sediment contamination; Gastropod; Community structure; Indonesia. 